UNIVERSITY OF CHITRAL JOURNAL OF LINGUISTICS AND LITERATURE

VOL. 5 | ISSUE I | JAN - JUNE | 2021

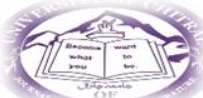

ISSN (E): 2663-1512, ISSN (P): 2617-3611

\title{
An Analysis of Hate Speech Tweets Against Women from a Socio-cognitive Discourse Perspective
}

\author{
Noor Mehboob \\ MS Applied Linguistics Research Scholar, FAST National University, Lahore \\ Dr. Urooj Fatima Alvi \\ Assistant Professor/Coordinator English Department \\ University of Education, Lahore
}

\begin{abstract}
The current study conducts a qualitative analysis of tweets based on hate speech directed at women in the Pakistani context using Van Dijk's Socio-cognitive approach (2016). The research's objective is to ascertain how cognition, social conditions, and discourse contribute to the establishment of a system that discriminates against women. The research employs Dijk's (2016) socio-cognitive approach to investigate the language of tweets. Using Twitter, ten tweets are collected as examples of hate speech. These tweets are from some of Pakistan's most powerful female journalists, politicians, and actresses. The research begins by examining the discursive structures that discriminate against women and then examines how cognitive structures shape this discourse. Finally, the discourse's social function is established. The analysis of tweets reveals that discourse is shaped by the tweeters' individual mental models and social cognition. Additionally, it was determined that sexist ideology is embedded in tweeters' mental models and socio-culturally shared knowledge, in which women are negatively represented. According to that they are viewed as objects of physical pleasure and are evaluated negatively based on their appearance rather than their ability, talent, hard work, or intelligence. Such an ideology breeds derogatory and discriminatory tweets, eventually resulting in a maledominated society. Male-dominated society, sexist ideology, and sexist speech combine to create a system that discriminates against women.
\end{abstract}

Keywords: hate speech tweets, critical discourse analysis, socio-cognitive approach

\section{Introduction}

According to Nik \& Esposito (2018), web participation has revolutionized the way we communicate and connect. Teenagers share information and connect with others through various platforms of social media communication including Twitter, Instagram and Facebook, 


\section{UNIVERSITY OF CHITRAL JOURNAL OF LINGUISTICS AND LITERATURE \\ VOL. 5 | ISSUE I | JAN - JUNE | 2021

WhatsApp, and others. Social media has many advantages and disadvantages. One of its major flaws is hate speech, also known as "Cyber Hate". Social media is rife with extremist and intolerant views, the use of derogatory or discriminatory language based on ethnicity, religion, nationality, race, or any other identity factor. Likewise, online hate against women is becoming a major social issue, according to recent media reports.

The current study conducts a qualitative analysis of hate speech tweets directed at women in the Pakistani context using a critical discourse analysis methodology. The study makes use of Van Dijk's socio-cognitive approach (2016) focusing on the psychological side. He makes a point of emphasizing the triad of discourse, cognition, and society. According to the sociocognitive perspective, the relationships between social and discourse structures are mediated by cognitive processes. Only the mental representations of language users as individuals and social members can establish a link between social and discourse structures (Wodak \& Meyer, 2009). Van Dijk argues that cognitive mediation is necessary to understand that how complex societal structures influence the structures of discourse. Such mediation can be characterized as shared knowledge and ideologies which exist in the minds of the individuals of a group and influence the mental models, eventually controlling the structures of the discourse. The research explicitly describes discourse structures i.e. metaphors, lexicon, word order, implications, and presuppositions, etc. in hate speech tweets, and then determines how cognitive structures shape this discourse.

\section{Research Objectives}

The following objectives are addressed in the research

i. To describe discourse structures in hate speech tweets systematically and explicitly, including lexicon, metaphors, word order, implications, presuppositions, and topics.

ii. To elucidate the role of individual mental models and socially shared knowledge in mediating between hate speech discourse structures and complex societal structures.

iii. To ascertain the extent to which cognition, social conditions, and discourse contribute to the establishment of a system that discriminates against women.

\section{Research Questions}

The study is guided by the following research questions: 
UNIVERSITY OF CHITRAL JOURNAL OF LINGUISTICS AND LITERATURE

VOL. 5 | ISSUE I | JAN - JUNE | 2021

a. What are the discourse structures in hate speech tweets which discriminate against women?

b. How do cognitive structures influence the content of hate speech tweets?

c. How do cognition, social conditions, and discourse all contribute to the establishment of a discriminatory and victimizing system for women?

\section{Research Gap}

The study analyses hate speech tweets directed towards women using Van Dijk's sociocognitive approach. The cognitive idea has previously been explored in racist, anti-racist, and political speech, but no relationship between cognitive structures and discourse or societal structures has been established in hate speech against women. In addition, in the Pakistani context, the use of hate speech against women on social media is increasing; nevertheless, there is relatively little research in this area. As a result, the goal of this study is to look at the cognitive and sociocultural processes that underpin this discourse.

\section{Literature Review}

\section{The Socio-cognitive Approach (SCA)}

Critical discourse studies relate discourse structures with social structures, but an important dimension was missing known as the 'sociocognitive dimension'. In Sociocognitive Discourse Studies (SCDS), social structures are related to discourse structures by using the sociocognitive interface. According to Dijk (1998a, 1998b, 2001, 2008, 2014 and 2016) sociocognitive discourse studies are related to the ongoing communicative event, social cognition, and ideologies and attitudes which exist in the minds of language users as members of the social group. The sociocognitive approach of Van Dijk is known as the 'DiscourseCognition-Society Triangle" (Wodak \& Meyer, 2009, p. 64) Dijk (2016) investigated the cognitive basis of Telegraph editorial regarding Immigration in the UK. Dijk conducted this research to know that why the text in the editorial had such a specific structure. The journalist of the editorial while writing it presupposed knowledge and particular ideological beliefs. The discourse structure in the editorial was actually controlled by the event, context, and mental models. The headline of the editorial summarized that the journalist has a positive attitude towards the actions of the government. Positive appraisal terms and metaphors in the editorial 
UNIVERSITY OF CHITRAL JOURNAL OF LINGUISTICS AND LITERATURE

VOL. 5 | ISSUE I | JAN - JUNE | 2021

depicted that the journalist has a positive mental model about that event. So, basically in this research, Dijk (2016) investigated how the discourse structure of a journalist is related to his cognition and society. He analyzed racist and anti-racist discourse in terms of the discoursecognition-society triangle. His research revealed that individual mental models and social cognition mediate between discourse and societal structures. He proved that the cognitive component is essential to CDA. Socially shared knowledge plays an important role in the production and comprehension of discourse. Dijk stated that to understand that how societal structures influence discourse structures, the mediation of cognition is necessary. "Such mediation is defined in terms of the shared knowledge and ideologies of group members and how they influence mental models that finally control the structures of individual discourse"(Wodak \& Meyer, 2009, p. 70).

Likewise, Ghachem (2015) attempted to highlight the social representations hidden in the discourse of the leader of the British Conservative Party. For this purpose, he selected David Cameron's pre-election addresses back in 2010. The methodological framework used in this research was again the sociocognitive approach and systematic functional linguistics (SFL). The research explored that Cameron interacted with the audience with common underlying beliefs, ideology, and knowledge. His discourse was shaped to win the votes and to ensure people that they share the same ideologies.

\section{Critical Discourse Analysis of Hate Speech Tweets against Women}

Spallaccia (2018) conducted qualitative research for the analysis of online misogyny on Twitter and Facebook. According to her, misogynistic speech is ignored by most analysts. Most of the researches focuses on xenophobic and racist content and ignores such crucial issues. The researcher used feminist critical discourse analysis to analyze the misogynistic hate speech. It focuses on the qualitative analysis of online abuse faced by six women belonging to three different countries i.e. Australia, Italy, and the USA. Analyzing the discourse, patriarchal ideologies were reaffirmed. It also revolved around different types of discrimination and gender prejudice hidden in discourse and suggested the use of effective educational tools which tackle this serious issue so that women can have a respectful conversation online. 


\section{UNIVERSITY OF CHITRAL JOURNAL OF LINGUISTICS AND LITERATURE \\ VOL. 5 | ISSUE I | JAN - JUNE | 2021

Elias \& Gurbanova (2018) analyzed the linguistic features of sexist hate speech on social media in the Tanzanian context. They discovered how gender preconceptions are reflected in social media conversation. To analyse the discourse, this study used a content analysis and critical discourse analysis technique and data was collected from the accounts of celebrities and public figures to discover the sexism in Tanzanian society.

Darweesh \& Abdullah (2016) investigated that language is a tool that is sometimes used to discriminate and abuse individuals of a particular group or society. It is also used to discriminate against women by portraying them negatively in society. In study, the authors analyzed the sexist speech of Donald Trump following the methodology of critical discourse analysis. It revealed Trump's sexist ideology that eventually results in producing sexist discourse. The structural, lexical, and rhetorical methods that result in the formation of discriminating and disparaging discourse were explored. To analyze Trump's opinions the author used Van Dijk's socio-cognitive framework (2006) and Mills' model of Sexism (2008). According to this research, Trump's ideology reflected males as superior and women as inferior. To devalue women Trump has used several lexical and rhetorical strategies. In his utterances, metaphors and lexicons having negative implications are explored.

The reviewed studies indicate that research has been conducted to investigate the cognitive notion in political speeches, racist and anti-racist discourse, but so far this aspect isn't investigated in hate speech against women. Some researchers have analyzed hate speech against women using the methodology of critical discourse analysis but the socio-cognitive aspect is not being explored yet.

\section{Materials and Methods}

The study is qualitative and empirical by collecting and interpreting non-numerical data. It utilizes user-generated content (tweets) as a research sample. Twitter data reveals that prominent Pakistani female politicians, journalists, and actors are the targets of hate speech. A total of ten tweets was gathered as examples of hate speech. These tweets were about powerful Pakistani female journalists, politicians, and actors. The research referred to these tweets as tweets $1,2,3$, etc. The research used the sampling technique of maximum variation to gain more insight into the target phenomenon. It is a type of purposive sampling that relies on the 


\section{UNIVERSITY OF CHITRAL JOURNAL OF LINGUISTICS AND LITERATURE \\ VOL. 5 | ISSUE I | JAN - JUNE | 2021

researcher's judgment. It is used to investigate perspectives ranging from the typical to the extreme. No specific type of hate speech tweets was targeted for collection. The sample was not collected based on the victim's age, social class, or occupation.

\section{Approach for Data Analysis}

The tweets data were analyzed by using the socio-cognitive approach by Van Dijk (2016) comprising of three basic levels. Firstly, it focused on the discourse structures of usergenerated hate speech tweets such as the characteristics of discourse structures like topic, lexicon, metaphors, syntax, word order, implications, pronouns, etc. Secondly, underlying individual mental models and shared ideologies and attitudes which shaped the discourse structures. Finally, it was investigated that how cognition, social conditions, and discourse contribute towards the establishment of a system where women are discriminated.

\section{Findings and Discussion}

\section{Tweet 1}

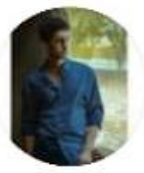

Afraz Alam @AFRAZA....24 Mar 2019 Mehwish hayat doesnt deserve Sitara e imtiaz She deserves uncle Imtiaz \#MehwishHayat \#sitaraeimtyaz

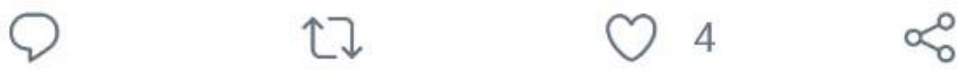

The socio-cognitive discourse analysis of the tweets indicates that hate speech against women is controlled by individual mental models and the social cognition of the tweeters. The sexist mindset and attitude of the tweeters, who objectify and trivialize women based on their gender and appearance, has influenced this conversation. The examination of the tweets reveals how discourse, society, and cognition form a triad that results in a system that discriminates against women.

The topic of the tweet is related to Mehwish Hayyat (a famous Pakistani celebrity) being awarded the third-highest civilian award Sitara-i-Imtiaz.

\section{Discursive Structures}




\section{UNIVERSITY OF CHITRAL JOURNAL OF LINGUISTICS AND LITERATURE \\ VOL. 5 | ISSUE I | JAN - JUNE | 2021

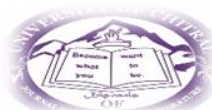

The tweet comprises mainly two sentences, both the sentences are active voice. In an active voice sentence, the stress is laid on the subject of the sentence. So here, the stress is on 'Mehwish Hayyat'. The use of words 'Sitara-i-Imtiaz and 'uncle Imtiaz' creates a rhyming scheme within a tweet to grab the attention of the readers. The technique of Satire is being used by the tweeter. In general, the tweet seems to fall in the humorous category but in reality, it derives contempt from the person reading the tweet. At the end of the tweet 'Hash tags' are used to lay emphasis on the topic of the tweet.

\section{Cognitive Structures}

The tweet is produced based on the context model of the tweeter who knows the situation and gives his opinion according to his interpretation of the situation. The current mental model of the tweeter about the event is negative. The use of the negative appraisal term 'doesn't deserve' reflects the negative opinion about the event in the event model. The use of satire 'she deserves uncle Imtiaz depicts the negative aspect of his mental model about Mehwish Hayyat being awarded the third-highest civilian award. Socioculturally shared knowledge is presupposed in the production and comprehension of this tweet regarding what women usually deserve in society. The tweet is based on a social norm that women actually deserve 'man', not a third highest civilian award. Such a norm is part of the underlying ideologies and attitudes of the tweeter.

\section{Social Function}

The tweet makes use of Satire and functions in deriving contempt and hatred from the readers for the actress. It implies that women are weaker and are not eligible for notable awards. In a male-dominated Pakistani society, power is exercised through discourse by portraying women as trivial beings. Such sexist ideology is part of socioculturally shared knowledge.

\section{Tweet 2}

Adam @rajaishtiaqturk·2 Nov 2014

Replying to@anilakhawaja

@anilakhawaja@PTIofficial

@ShireenMazari1@MunazaHassan

\#shireen mazari is not a woman, she equal

to a man!, shame less woman
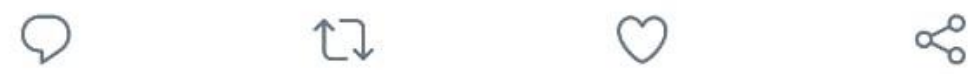


\section{UNIVERSITY OF CHITRAL JOURNAL OF LINGUISTICS AND LITERATURE \\ VOL. 5 | ISSUE I | JAN - JUNE | 2021

This tweet is related to Shireen Mazari, who is currently a Federal Minister of Human Rights.

\section{Discursive Structures}

The tweeter uses the negative lexicalization 'shameless woman' to represent Shireen Mazari. The tweet begins with a negative clause. Firstly, he emphasizes 'what she is not' and then on 'what she is. The tweeter exclaims that Mazari is equal to a man. An exclamatory mark is used to lay emphasis and to grab the attention of the readers. The addresser makes use of a rhetorical device known as Antithesis to attain a contrasting effect. First of all the tweeter negates that Mazari is a woman but then at the end of a sentence he uses the term woman for her. So, he has placed two contrasting ideas parallel to one another.

\section{Cognitive Structures}

Specific knowledge related to Shireen Mazari is presupposed in the production of this discourse. Based on that knowledge the tweeter uses negative lexicalization for Mazari, this negative lexicalization depicts the negative aspects of his mental model related to Mazari. Similarly, the use of antithesis also demonstrates a negative representation of Mazari in the mental model of the tweeter. The tweet is based on a norm that a woman who tries to be equal to a man is not actually a woman and is a shameless creature. Such norm is part of the ideology of the individual and sociocultural beliefs. It is implicitly stated that Mazari is shameless just because she tries to be equal to a man. This implicit information is not in the discourse and exists in the underlying mental models of the tweeter. Based on sociocultural knowledge, the mental model of tweeter differentiates between tasks and behavior of men and women within a society. The overall meaning of the tweet is negative.

\section{Social Function}

Male dominance is transparent in the discursive and cognitive structures of the discourse. In the Pakistani context, a woman who tries to be equal to a man is considered shameless. This tweet discriminates against the female politician by using discriminatory and derogatory terms. 
UNIVERSITY OF CHITRAL JOURNAL OF LINGUISTICS AND LITERATURE

VOL. 5 | ISSUE I | JAN - JUNE | 2021

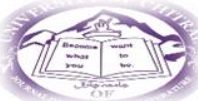

\section{Tweet 3}

This comment appears under the tweet of a Pakistani actress.

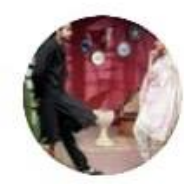

Outspoken@childhoodmatric·18 Feb

Replying to @MehwishHayat

Sex bomb

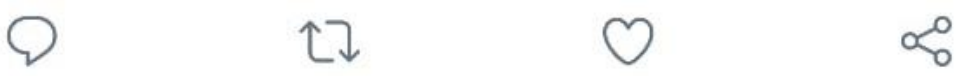

\section{Discursive Structures}

The tweeter uses the negative term for the actress. The metaphor 'sex bomb' refers to a sexually attractive woman. In this tweet, the actress is objectified as she is viewed as a mere object of sexual desire. Sex bomb is a slang word in the English language.

\section{Cognitive Structures}

The metaphor 'sex bomb' reflects the negative aspect of the mental model regarding women. In the mental model of the tweeter, an actress is an object of sexual and physical desire. He does not view her talent or personality. He views the actress as a slab of meat who exists only for male consumption. The tweeter evaluates the actress based on her sexual appeal. This indicates that in his mental model and socioculturally shared knowledge women are sexual objects.

\section{Social Function}

Socioculturally shared knowledge is presupposed in the production of this discourse. The tweeter according to his mental model and social cognition views women as an object of physical pleasure. He does not evaluate women based on their personality and talent. When a woman is viewed as a dehumanized sexual object of the commodity and this eventually results in violence against the woman resulting in humiliation, harassment, and sexual assault.

\section{Tweet 4}

This tweet is related to Shireen Mazari who is currently Federal Minister of Human Rights.

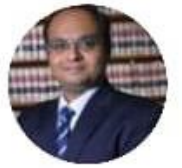

@Rehantt330@rehantt330·27 Feb

Replying to@ShireenMazari1

Why is this clown our human rights minister.

Check out the colorful wig on her head.

She's representing Pakistan? 


\section{UNIVERSITY OF CHITRAL JOURNAL OF LINGUISTICS AND LITERATURE \\ VOL. 5 | ISSUE I | JAN - JUNE | 2021

\section{Discursive Structures}

The tweeter has used an insulting metaphor 'clown' for a female politician. 'Why is this clown our human rights minister' is a rhetorical question which does not prompt an answer. It actually lays emphasis on a point and makes a reader contemplate. The deictic expression 'this is used to refer to Shireen Mazari. 'Check out the colorful wig on her head' is an irony. The tweeter used this statement to show contempt and hatred towards her physical appearance. 'She is representing Pakistan?' is an ironic rhetorical question. This question does not demand an answer from the readers. The implicit meaning in this question is that she should not be representing Pakistan as she is not capable enough.

\section{Cognitive Structures}

A large amount of knowledge related to Sheeren Mazari is presupposed in the production of this discourse. The deictic expression 'this' refers to a presupposed information in the context model. The use of the metaphor 'clown' shows the negative aspects of the mental model of the tweeter. The word clown is used for a fool or comic entertainer with an unsophisticated appearance. So, negative connotations are attached to it when used for someone who is not a professional clown. According to social cognition and the individual mental model of the tweeter, the physical appearance of a woman matters more than her talent and intelligence. Therefore, the tweeter negatively evaluates her based on her appearance. The tweeter delivers implicit meaning through words based on his context model according to the current situation. The pragmatic and semantic models shape the ironical statements of the tweeter.

\section{Social Function}

Socioculturally shared knowledge is presupposed in the production of this discourse. According to social cognition and individual mental model, the tweeter views the female politician as an object. He negatively evaluates her based on her appearance and uses a derogatory term for her. Such a norm is part of society where women are seen as mere objects and are evaluated based on their looks. This tweet results in discriminating women within a society based on their looks. 
UNIVERSITY OF CHITRAL JOURNAL OF LINGUISTICS AND LITERATURE

VOL. 5 | ISSUE I | JAN - JUNE | 2021

\section{Tweet 5}

"She along with her mother obtained the seat for National Assembly by stooping down to new lows.. Don't expect anything SANE and LITERATE from these shameless PUPPETS"

This tweet is related to a well-known Pakistani politician Maryam Aurangzeb and her mother Tahira Aurangzeb, both are the members of National Assembly.

\section{Discursive Structures}

Here in the tweet, the tweeter makes use of the metaphor 'stooping down' for both the female politicians. Here, stooping down means to do something which is morally and ethically wrong. Similarly, the metaphor 'puppets' is used to indicate that both women are controlled by some external force. These metaphors have negative implications. To delineate these two female politicians the tweeter has used negative lexicalization 'shameless puppets'. The syntax of the sentence indicates that the stress is mainly on 'She' i.e. Maryam Aurangzeb. Words sane, literate, and puppets are capitalized to lay stress on them or to capture the attention of the readers.

\section{Cognitive Structures}

A vast amount of political knowledge is presupposed in the production of this tweet. The metaphors 'PUPPETS' and 'stooped down' indicate the negative aspects of the mental model by representing the negative characteristics of female politicians. Use of the word 'Puppet' indicates that in the mental model of the tweeter women are controllable beings. The tweet is basically based on two significant norms, first one is that female politicians gain success by losing their moral values. The second one is that they are puppets controlled by some external force and are objects or commodities. The tweeter emphasizes that the fore-mentioned politicians are submissive. Such norms are part of the underlying ideologies and attitudes of a tweeter regarding women. Negative lexicalization like 'shameless' reveals the negative mental model of the tweeter regarding female politicians. The use of the phrase 'new low' presupposes that there were such disappointing acts by these female politicians in the past. In this way, this activates the old mental model of the readers.

\section{Social Function}




\section{UNIVERSITY OF CHITRAL JOURNAL OF LINGUISTICS AND LITERATURE \\ VOL. 5 | ISSUE I | JAN - JUNE | 2021

This tweet deteriorates the positive image of female Pakistani politicians by implicitly portraying that they have to sacrifice their good morals to gain a seat in National Assembly. So, in the context model of the readers, female politicians are trivialized. This tweet strengthens male domination within a society by characterizing women as a misfit in politics.

\section{Tweet 6}

\section{Pakistani @Abdulah530895....25 Feb Replying to @MehwishHayat Vulgar bitch}

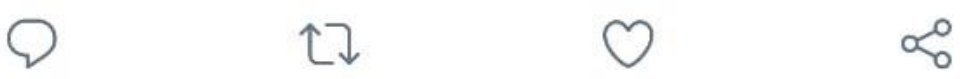

This tweet is related to one of the most popular Pakistani actresses.

\section{Discursive Structures}

This tweet comprises two words. The tweeter uses the metaphor 'bitch' to exploit the identity of the actress. This metaphor is modified by the adjective 'vulgar' that shows the intensity of hatred towards the addressee. The word 'bitch' is a curse word used in the English language. Negative connotations are attached to it. In this context, it implicitly means an indecent, vulgar, or malicious woman.

\section{Cognitive Structures}

The use of negative terms 'vulgar bitch' represents the negative aspects of the mental model of the tweeter. Negative connotations are attached to the word 'bitch' and these connotations are not explicit in the discourse. They are present in the underlying mental models

of the addresser and the readers. Readers having the same socio-cultural knowledge can understand it. The tweet is based on the norm that female actresses are indecent and vulgar individuals of society. Such a norm is part of the underlying ideology of the tweeter. The overall negative opinion of the tweeter about the actress is represented in his mental model.

\section{Social Function}

The discursive and cognitive structures of the tweet function in the humiliation of the actress. It provokes verbal and physical violence against actresses. The tweeter exercises power through the tweet and targets the actress. In a male-dominated Pakistani society, females 


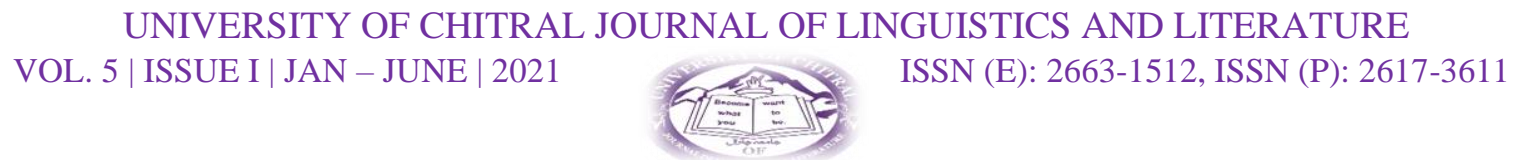

working in media are considered vulgar. On the other hand, this concept is not associated with males working in media. So, this tweet functions in discrimination against women.

\section{Tweet 7}

This tweet appears as a reply to Bakhtawar Bhutto Zardari’s tweet.

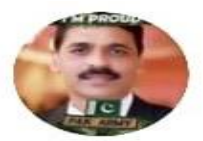

Sardar shah jafri @Sardarsh... · 1 Mar

Replying to@BakhtawarBZ

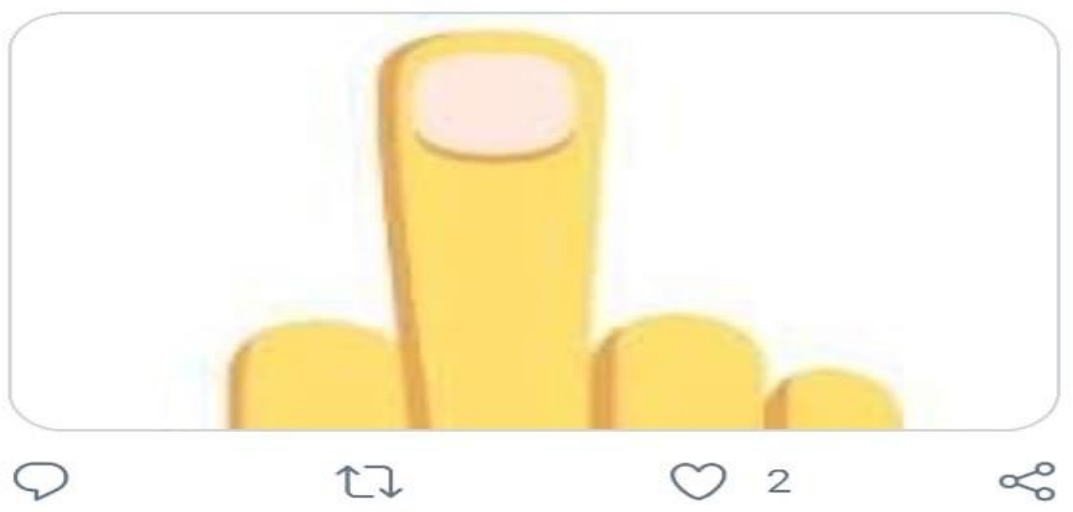

\section{Semiotic Structures}

The tweeter has used a hand gesture to show contempt and hatred towards the addressee. In the Pakistani context, this middle finger gesture is considered extremely obscene when used for women. The person receiving the gesture is threatened, sexually harassed, or intimidated in this way. The gesture is used to dehumanize and trivialize the female politician. It is frequently used against females on social media to sexually harass them.

\section{Cognitive Structures}

The use of this gesture indicates a negative attitude towards the female politician. Such an attitude is part of the sexist ideology of the tweeter. In the mental model of the tweeter, a woman is seen as a sexual object used to accomplish the physical desires of men. Socioculturally shared knowledge is also presupposed in the production of this discourse. The tweeter has knowledge that in the Pakistani context, this gesture can intimidate or threaten a woman. So, he uses it to silent the opinion of a female politician. It indicates a negative aspect of the mental model of the tweeter regarding women.

\section{Social Function}




\section{UNIVERSITY OF CHITRAL JOURNAL OF LINGUISTICS AND LITERATURE \\ VOL. 5 | ISSUE I | JAN - JUNE | 2021

The sexist ideology of the tweeter is reflected in this discourse. Such a discourse can incite physical and verbal abuse against women. It also encourages sexual harassment, eventually leading to sexual assault. The tweet signals that the dominant and powerful group within a society is the 'male group' which can intimidate, threaten, and sexually abuse the weaker 'female group'.

\section{Tweet 8}

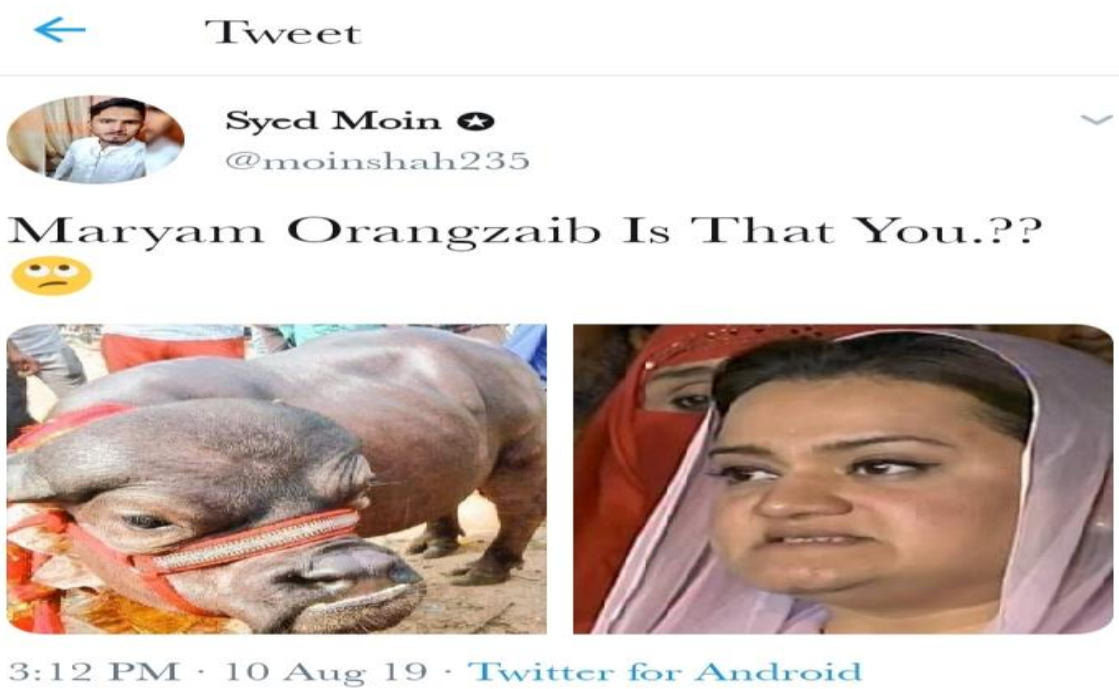

This tweet targets a female Pakistani politician Maryam Aurangzaib.

\section{Discursive and Semiotic Structures}

The tweet comprises two pictures and a caption. The caption 'Maryam Orangzaib is that you?' is a rhetorical question that does not require an answer from the addressee. The literary device of Satire has been used in the tweet. The purpose of the tweet is to make fun of the female politician and to derive contempt from the readers. In the pictures, the physical appearance of the political figure is being ridiculed. The two pictures are juxtaposed to derive similarity in appearance. An overall negative meaning is delivered through the tweet. In the Pakistani context, a comparison of a woman with a bull has negative connotations.

\section{Cognitive Structures}

The tweet makes use of Satire, where contempt is derived from the readers by making fun of the political figure. So, this knowledge of the use of language according to the situation exists in the context model of the tweeter. The use of Satire indicates the negative aspect of the 


\section{UNIVERSITY OF CHITRAL JOURNAL OF LINGUISTICS AND LITERATURE \\ VOL. 5 | ISSUE I | JAN - JUNE | 2021

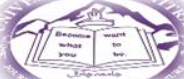

mental model of the tweeter regarding Maryam Aurangzaib. The implicit meaning is not apparent in the tweet but is present in the underlying mental model of the tweeter. The readers sharing the same sociocultural knowledge will be able to comprehend the implicit meaning based on their mental model. The tweet reflects the tweeter's ideology where he negatively evaluates the female politician based on her looks. Hence, treats her as an object or commodity.

\section{Social Function}

It is an example of user-generated content in which women are bullied based on their looks. It shows that in Pakistani context women are seen as an object, ranked based on their physical appearance. It results in derogatory terms against women and eventually stimulates violence against women. Sociocultural knowledge and individual mental models influence the discourse produced in this tweet.

\section{Tweet 9}

\section{吉布蘭 @jibrandalvi89·18 Feb}

Replying to@MehwishHayat

Pure thot with dirty heart

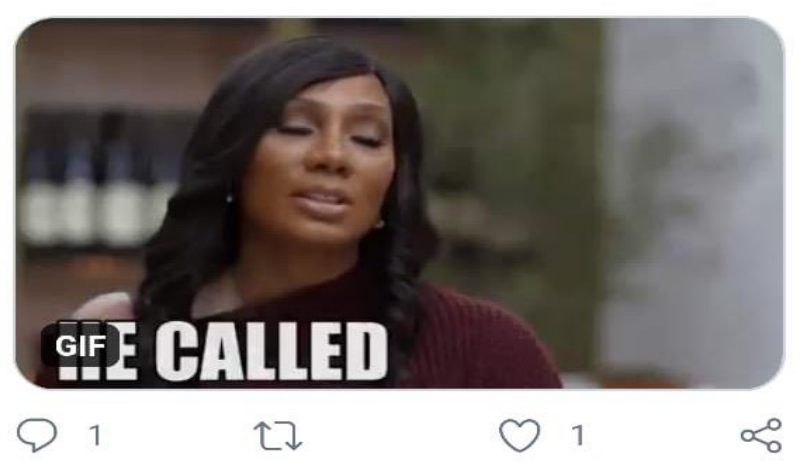

This comment appears on the official Twitter account of Pakistani actress 'Mehwish Hayyat' who won the third-highest Civilian award 'Sitara-i-Imtiaz.

\section{Discursive Structures}

The tweeter makes use of the derogatory and offensive metaphor 'Thot' for the actress. Negative Lexicalization is used to delineate her. That is the acronym for 'That hoe over there' and is extremely derogatory in nature. The prepositional phrase 'with dirty heart' acts as an adjective and describes the noun phrase 'pure thot'. It overall indicates an extremely 


\section{UNIVERSITY OF CHITRAL JOURNAL OF LINGUISTICS AND LITERATURE \\ VOL. 5 | ISSUE I | JAN - JUNE | 2021

offensive meaning. The sentence is not complete, as it only comprises phrases. This kind of syntactical structure is commonly used in social media discourse where language is used informally most of the time.

\section{Cognitive Structures}

The tweeter presupposes specific knowledge related to the actress and then formulates his own opinion based on underlying ideologies and socioculturally shared knowledge. The tweet indicates an overall negative opinion about the actress in the mental model. The metaphor 'thot' shows the negative aspect of the mental model. The actress is described as 'thot' because of a general sociocultural knowledge related to the profession of acting. In the mental model of tweeter actresses are submissive and objectified individuals. The tweet is based on a social norm that actresses do not have good moral values and they lower themselves ethically to gain fame. This norm is part of individual mental models and socio-culturally shared knowledge between groups or individuals within a group.

\section{Social Function}

The tweeter uses offensive language for the actress to humiliate her. The discursive and cognitive structures demonstrate that actresses are considered unethical individuals within Pakistani society. Immorality is associated with the females working in this field. It discriminates and humiliates the actress. It encourages the use of offensive language for the actresses.

\section{Tweet 10}

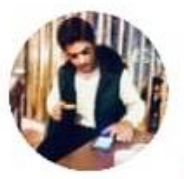

\section{Farooq Tahir @M_Farooq_T... 31 Jan} Replying to @PTlofficial and @ShireenMazari1 Trolley

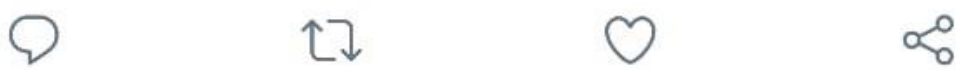

Federal Minister of Human Rights, Shireen Mazari is targeted in this tweet.

\section{Discursive Structures}

The tweeter makes use of the metaphor 'trolley' to describe Shireen Mazari. In the Pakistani context, when this word is used for a woman it has negative connotations. In this 


\section{UNIVERSITY OF CHITRAL JOURNAL OF LINGUISTICS AND LITERATURE \\ VOL. 5 | ISSUE I | JAN - JUNE | 2021

context, a trolley means a person who is obese or overweight. So, negative lexicalization is used in this tweet. It portrays the body shame against woman.

\section{Cognitive Structures}

The use of the metaphor 'trolley' to describe the female politician shows the negative aspect of the mental model. Similarly, the connotative meaning of the trolley is not implicit in the discourse. It exists in the underlying mental model of the tweeter. The readers having the same sociocultural knowledge can comprehend the implicit meaning. The tweet demonstrates the attitude of the tweeter towards the female politician. In the mental model of the tweeter, the way a female politician looks is more important than her performance. This is an attitude part of his sexist ideology.

\section{Social Function}

This tweet indicates how women are devalued based on their looks in a society where women are seen as an object. They are judged only on the basis of their appearance. Such discourse eventually results in body shaming and humiliation of women within a society.

\section{Conclusion}

The present research explored how discourse, cognition, and society form a triad resulting in a system where women are discriminated against. The results indicated that discourse in hate speech tweets is actually controlled by cognitive and societal structures. It highlighted the discursive structures like metaphors, negative implications, syntax, word order, satire, deictic expressions, adverbs, adjectives, presuppositions, negative connotations, and rhetorical questions which are examples of hate speech. The tweeters used offensive, derogatory and discriminatory discourse for various public figures, politicians, actresses, and journalists. Such discourse is dominated by the speakers' sexist mindset, which views women as inferior and objectifies them based on their appearance. Women in Pakistani society are considered as objects to fulfil physical wants, according to the above-mentioned discussion. They are discriminated against because they are judged on their appearance and gender rather than their ability, intelligence, and competence. These ideals are part of the tweeters' mental model and social cognition. The study also revealed how context models influence dialogue. In Pakistani society, the tweets foment hostility and discrimination towards women. This hostility leads to physical abuse, verbal abuse, 


\section{UNIVERSITY OF CHITRAL JOURNAL OF LINGUISTICS AND LITERATURE \\ VOL. 5 | ISSUE I | JAN - JUNE | 2021

sexual harassment, and sexual assault against women, eventually leading to a male-dominated culture where women are discriminated against. The findings of this study may be useful to social scientists, humanitarians, and activists because they expose the root causes of violence and prejudice against women. Knowing what's causing the problem will eventually lead to remedies. Due to time restrictions, the sample size was kept minimal in this study. By extending the sample size, future researchers will be able to acquire a better understanding of this phenomenon. Furthermore, the cognitive aspect can be thoroughly investigated, which can aid in the comprehension of complicated human behaviours and discourse.

\section{References}

Darweesh, A. D., \& Abdullah, N. M. (2016). A Critical Discourse Analysis of Donald Trump's Sexist Ideology. Journal of Education and Practice, 7(30), 87-95. https://files.eric.ed.gov/fulltext/EJ1118939.pdf

Dijk, T. A. V. (1998a). Ideology. A Multidisciplinary Approach. London: Sage Publications.

Dijk, T. A. V. (1998b). Ideology and Discourse. London: Sage Publications.

Dijk, T. A.V. (2001). Critical discourse analysis. In D. Schiffrin and H. Hamilton (eds.),Handbook of Discourse Analysis. Oxford: Blackwell.

Dijk, T. A. (2008). Discourse and Context. A Sociocognitive Approach. Cambridge: University Press

Dijk, T. A.V. (2014). Discourse and knowledge. A sociocognitive approach. New York: Cambridge University Press.

Dijk, T. A. V. (2016). 'Critical Discourse Studies: A Sociocognitive Approach.' In Methods for Critical Discourse Analysis, ed. By Ruth Wodak \& Michael Meyer, 62-86, selected 6267, 75-80. London: Sage.

Elias, S., \& Gurbanova, N. (2018). Relocating gender stereotypes online: Critical analysis of sexist hate speech in selected social media. Proceedings of the International Conference on Language Phenomena in Multimodal Communication (KLUA 2018). Doi:10.2991/klua-18.2018.40 
UNIVERSITY OF CHITRAL JOURNAL OF LINGUISTICS AND LITERATURE

VOL. 5 | ISSUE I | JAN - JUNE | 2021

Ghachem, I. (2015). A Sociocognitive Approach to Agency Framing in David Cameron's 2010 Pre-election Discourse. Critical Approaches to Discourse Analysis across Disciplines, $7(2)$, 263-282.http://www.lancaster.ac.uk/fass/journals/cadaad/wpcontent/uploads/2015/08/Volume-7_Ghachem.pdf

KhosarviNik, M., \& Esposito, E. (2018). ONLINE HATE, DIGITAL DISCOURSE AND CRITIQUE: EXPLORING DIGITALLY-MEDIATED DISCURSIVE PRACTICES OF GENDER-BASED HOSTILITY. Special issue on Narrating hostility, challenging hostile Narratives, 14(1), 45-68. Doi: 10.1515/lpp-2018-0003

Wodak, R., \& Meyer, M. (2009). Methods for Critical Discourse Analysis ( $2^{\text {nd }}$ ed.). London: Sage. Linguistics \& Literature, Pakistan. This article is an open access article distributed under the terms and conditions of the Creative Commons Attribution (CC BY) (http://creativecommons.org/licenses/by/4.0/). 